\title{
Cordiamyia globosa Maia (Diptera, Cecidomyiidae), flutuação populacional e parasitóides (Hymenoptera) associados
}

\author{
Valéria Cid Maia ${ }^{1}$ \\ Marcelo T. Tavares ${ }^{2}$
}

\begin{abstract}
Cordiamyia globosa Maia (Diptera, Cecidomyiidae), populational flotation and associated parasitoids (Hymenoptera). Populational flotation of Cordiamyia globosa Maia, 1996 - a gall maker species - was studied during 12 months using its galls as parameter. The maximum and medium number of galls/leaf/month was obtained, as well as the percentage of attacked leaves. Eight species of parasitoid Hymenoptera were associated with the gall maker. Seasonal rates of parasitoidism are given.

KEY WORDS. Cecidomyiidae, Diptera, Cordiamyia globosa, Hymenoptera, gall
\end{abstract}

Cordiamyia globosa Maia, 1996 é um cecidomiídeo que induz galhas foliares em Cordia verbenacea DC. (Boraginaceae), planta abundante na Restinga da Barra de Maricá, Rio de Janeiro, ocorrendo nos primeiro e segundo cordões arenosos e na restinga aberta (SILVA \& SOMNER 1984). Tais galhas, encontradas principalmente na superfície inferior das folhas, estão descritas e ilustradas em MAIA (1996).

Em associação com as galhas de Cecidomyiidae é comum encontrar-se himenópteros parasitóides, hemípteros predadores, lepidópteros e coleópteros inquilinos, e outros (GAGNÉ 1994; MAIA 1995a,b, 2000; MAIA \& MONTEIRO 1999).

O objetivo deste trabalho é estudar a flutuação populacional do cecidomiídeo galhador e a entomofauna associada às suas galhas, determinando o hábito alimentar das espécies de insetos encontradas.

\section{MATERIAL E MÉTODOS}

No periodo de junho/1997 a maio/1998, foram realizadas excursões mensais à Restinga da Barra de Maricá, Rio de Janeiro. Para o estudo da flutuação populacional de C. globosa, as galhas foram utilizadas como parâmetro, uma vez que um único indivíduo galhador desenvolve-se no interior de cada uma delas. A cada excursão, 10 representantes da planta hospedeira (escolhidos aleatoriamente a cada mês) eram vistoriados. Para cada representante, era verificado o número de galhas de $C$. globosa presentes em 100 folhas (escolhidas também aleatoriamente, galhadas ou não), totalizando portanto 1000 folhas examinadas. A partir deste procedimento era obtido o número mensal máximo de galhas por folha. O número médio de galhas/folha/mês era calculado dividindo-se o número total de galhas contadas no mês pelo número total de folhas vistoriadas.

1) Departamento de Entomologia, Museu Nacional. Quinta da Boa Vista, São Cristóvão, 20940-040 Rio de Janeiro, Rio de Janeiro, Brasil. Bolsista CAPES.

2) Departamento de Ciências Exatas e Naturais, Centro Universitário de Araraquara. Caixa Postal 68, 14801-320 Araraquara, São Paulo, Brasil. 
O estudo da entomofauna associada às galhas de $C$. globosa procedeu-se da seguinte maneira.

No campo: mensalmente, 100 galhas eram coletadas (as primeiras 100 contadas na etapa anterior). Nos meses em que a abundância das mesmas não alcançou este valor, coletou-se um número o mais próximo possível do estipulado. As galhas coletadas eram transportadas em sacos plásticos fechados para o laboratório de Diptera do Museu Nacional, Universidade Federal do Rio de Janeiro, onde procedeu-se a criação dos insetos.

No laboratório: as galhas destinadas à criação eram acondicionadas em recipientes plásticos, contendo no fundo uma camada de papel absorvente umedecido e fechados com tela fina de "nylon". De segunda a sexta, esses recipientes eram vistoriados e os insetos adultos encontrados nos mesmos eram retirados, separados em morfo-espécie e fixados em álcool 70\%. Este material encontra-se depositado na coleção do Museu Nacional.

As galhas das quais emergiram outros insetos que não o galhador eram dissecadas sob estereomicroscópio para verificação dos restos dos organismos contidos no seu interior e determinação do hábito das espécies associadas.

Taxas sazonais de parasitoidismo eram calculadas a partir da emergência dos parasitóides e também a partir da dissecção de galhas (quando estas ressecavam antes da emergência de seus ocupantes). A dissecção permitia a verificação do número de galhas que continha himenópteros parasitóides, independentemente do sucesso da criação. Como para cada estação do ano foram realizadas três coletas, os valores obtidos para as mesmas foram somados afim de se obter um $\mathrm{N}$ maior, e a partir deste total foi calculado o percentual de galhas com parasitóides.

\section{RESULTADOS}

As galhas de Cordiamyia globosa ocorreram em todos os meses do ano, sendo mais abundantes no período de maio a julho, com destaque para o mês de junho, época na qual C. globosa atingiu seu pico populacional (Fig. 1). Este período corresponde a parte do outono e parte do inverno. Após o qual, a população de $C$. globosa manteve-se baixa, atingindo os menores níveis no verão, época caraterizada por altas temperaturas e ressecamento da vegetação. No outono, as temperaturas mais amenas favorecem a recuperação das plantas que rebrotam. Com a formação de novas folhas, aumenta a disponibilidade do recurso utilizado pelo galhador. No início do inverno, condições semelhantes são observadas, o que justificaria o padrão observado.

As folhas atacadas continham de 1 a 17 galhas. Apesar deste grande intervalo, o número médio mensal de galhas por folhas atacadas variou pouco, entre $1,09 \mathrm{e}$ 2,08 (Tab. I). O número de folhas atacadas variou entre 25 e 260 , o que corresponde a $2,5 \%$ e $26 \%$ do total de folhas vistoriadas (Tab. II). Estes resultados sugerem que quando há um aumento no número de galhas e portanto na população de C. globosa, ocorre um aumento correspondente no número de folhas atacadas, em detrimento da concentração de galhas em uma mesma folha. A ocorrência de poucas galhas em diversas folhas poderia ser resultado da pressão do parasitoidismo, uma vez que a disposição espaçada do recurso dificultaria a ação dos parasitóides, porque implicaria em um maior gasto de tempo na busca do hospedeiro. 


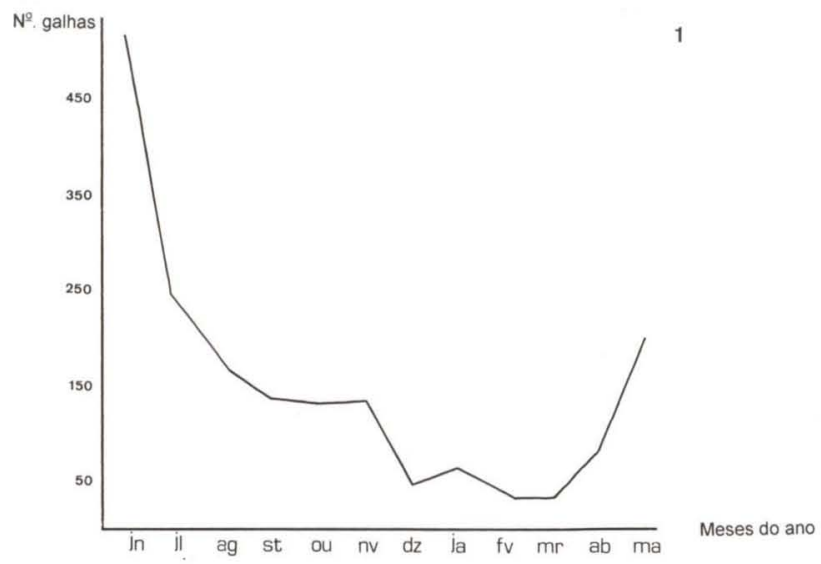

Fig. 1. Flutuação das galhas de Cordiamyia globosa, no período de junho/1997 a maio/1998, na Restinga da Barra de Maricá, Rio de Janeiro.

Tabela I. Número máximo e médio de galhas de Cordiamyia globosa por folha atacada, no periodo de junho/1997 a maio/1998, na Restinga da Barra de Maricá, Rio de Janeiro.

\begin{tabular}{lrc}
\hline \multicolumn{1}{c}{ Mês } & Número máximo de galhas/folha & Número médio de galhas/folha atacada \\
\hline Junho & 17 & 2,08 \\
Julho & 5 & 1,60 \\
Agosto & 8 & 1,59 \\
Setembro & 11 & 1,64 \\
Outubro & 6 & 1,62 \\
Novembro & 7 & 1,80 \\
Dezembro & 14 & 1,92 \\
Janeiro & 5 & 1,66 \\
Fevereiro & 3 & 1,32 \\
Março & 3 & 1,09 \\
Abril & 3 & 1,28 \\
Maio & 5 & 1,58 \\
\hline
\end{tabular}

As maiores médias do número de galhas por folha e o maior número de folhas atacadas foram registrados em junho, período no qual a população de $C$. globosa atingiu seu pico.

Quanto à entomofauna associada, observou-se que esta era constituída exclusivamente de himenópteros parasitóides (8 espécies) - Synopeas sp.; Lyrcus sp.; Pteromalidae não determinado; Torymus sp.; Torymoides sp.; Galeopsomyia sp.; Cirrospilus sp. e Eurytoma sp. (Tab. III)-diferindo de outras galhas já estudadas na região, para as quais foi assinalada a presença de coleópteros, lepidópteros e outros cecidomiídeos inquilinos e predadores (MAIA 1995a,b, 2000; MAIA \& MONTEIRO 1999).

Todas as espécies de himenópteros associadas à C. globosa agiram como parasitóides primários. Dentre estas, Synopeas sp. e Torymus sp. destacaram-se 
Tabela II. Número de folhas atacadas por Cordiamyia globosa no periodo de junho/1997 a maio/1998, na Restinga da Barra de Maricá, Rio de Janeiro.

\begin{tabular}{lcc}
\hline \multirow{2}{*}{ Mês } & \multicolumn{2}{c}{ Folhas atacadas } \\
\cline { 2 - 3 } & Número & Porcentagem (\%) \\
\hline Junho & 260 & 26,0 \\
Julho & 160 & 16,0 \\
Agosto & 103 & 10,3 \\
Setembro & 84 & 8,4 \\
Outubro & 82 & 8,2 \\
Novembro & 77 & 7,7 \\
Dezembro & 26 & 2,6 \\
Janeiro & 36 & 3,6 \\
Fevereiro & 25 & 2,5 \\
Março & 33 & 3,3 \\
Abril & 64 & 6,4 \\
Maio & 152 & 15,2 \\
\hline
\end{tabular}

Tabela III. Espécies de himenópteros parasitóides associados a Cordiamyia globosa no período de junho/1997 a maio/1998, na Restinga da Barra de Maricá, Rio de Janeiro.

\begin{tabular}{ll}
\hline \multicolumn{1}{c}{ Familia } & \multicolumn{1}{c}{ Espécie } \\
\hline $\begin{array}{l}\text { Platygasteridae } \\
\text { Pteromalidae }\end{array}$ & Synopeas sp. \\
& Lyrcus sp. \\
& Gênero e espécie não \\
determinados \\
Torymidae & Torymus sp. \\
& Torymoides sp. \\
Eulophidae & Galeopsomyia sp. \\
& Cirrospilus sp. \\
Eurytomidae & Eurytoma sp. \\
\hline
\end{tabular}

como as mais abundantes e as mais freqüentes, tendo sido obtidas em todos os meses do ano. A taxa de parasitoidismo foi mais alta no inverno, período no qual havia maior oferta de galhas (Tab. IV). Espécies dos gêneros dos calcidóideos identificados já foram constatadas em galhas de Cecidomyiidae (GRISSEL 1995; BOUCEK \& Heydon 1997; SChauff et al. 1997; DigiUlio 1997). Synopeas Foerster, 1856, assim como outros gêneros de Platygastrinae, tem sido constatadas como parasitóides primários de Cecidomyiidae (MASNER 1993).

Para a Restinga da Barra de Maricá, uma espécie não determinada de Galeopsomyia Girault, 1916 e outra de Eurytoma Illiger, 1807 já haviam sido registradas em galhas de Bruggmannia spp. (MAIA \& MONTEIRO 1999).

O hiperparasitoidismo, comumente verificado em galhas, como por exemplo em Guapira opposita (MAIA \& MONTEIRO 1999), não foi observado em Cordia verbenacea, apesar das altas taxas de parasitoidismo. Como muitas espécies de Eurytoma e Cirrospilus Westwod, 1832 estão mais relacionadas à uma condição 
específica (hospedeiros protegidos, por exemplo) do que à especificidade de hospedeiro, esperava-se a ocorrência de hiperparasitoidismo envolvendo pelo menos estas espécies.

Tabela IV. Relação das taxas sazonais de parasitoidismo em Cordiamyia globosa no periodo de junho/1997 a maio/1998, na Restinga da Barra de Maricá, Rio de Janeiro.

\begin{tabular}{lc}
\hline \multicolumn{1}{c}{ Estação do ano } & Taxas de parasitoidismo (\%) \\
\hline Primavera & 42,68 \\
Verão & 31,48 \\
Outono & 45,05 \\
Inverno & 79,36 \\
\hline
\end{tabular}

AGRADECIMENTOS. Ao Dr. John La Salle (International Institute Entomology, Reino Unido) pela identifícação de parte dos himenópteros.

\section{REFERÊNCIAS BIBLIOGRÁFICAS}

Boucek, Z. \& S.L. Heydon. 1997. Pteromalidae, p. 541-692. In: G. Gibson; J.T. Huber \& J.B. WoOlley (Eds). Annotated keys to the genera of Nearetic Chalcidoidea (Hymenoptera). Ottawa, NRC Research Press, 794p.

DigiUlıo, J.A. 1997. Eurytomidae, p. 477-495. In: G. GiBSon; J.T. HubER \& J.B. WoOlley. Annotated keys to the genera of Nearctic Chalcidoidea (Hymenoptera). Ottawa, NRC Research Press, 794p. GaGné, R.J. 1994. The Gall Midges of the Neotropical Region. Ithaca, Cornell Univ. Press, 352p.

Grisselt, E.E. 1995. Torymynae (Hymenoptera: Chalcidoidea: Torymidae): A redefinition, generic classification, and annotated World catalog of species. Mem. Entomol. Internat. 2: 1-470.

MAIA, V.C. 1995a. Dois gêneros novos de Cecidomyiidae (Diptera) associados à Myrtaceae, na Restinga da Barra de Maricá, Rio de Janeiro, Brasil. Revta bras. Zool. 12 (3): 567-574.

- 1995b. Chaves para classificação de galhas de Cecidomyiidae (Diptera) em Myrtaceae na Restinga da Barra de Maricá, Rio de Janeiro. Revta bras. Zool. 12 (4): 1009-1013.

-1996. Cordiamyia globosa gen.n. e sp.n. (Diptera, Cecidomyiidae, Cecidomyiidi) associado com Cordia verbenacea DC. (Boraginaceae) no Brasil. Revta bras. Zool. 13 (3): 579-583.

-2000. Artrópodes associados às galhas de Cecidomyiidae (Diptera) em Eugenia rotundifolia (Myrtaceae) e Clusia lanceolata (Clusiaceae) em uma restinga do Rio de Janeiro, Brasil. Iheringia, Série Zool., (87): 75-79.

MAIA, V.C. \& R.F. MonTEIRo. 1999. Espécies cecidógenas (Diptera: Cecidomyiidae) e parasitóides (Hymenoptera) associadas a Guapira opposita (Vell.) Reitz. (Nyctaginaceae) na Restinga da Barra de Maricá, Rio de Janeiro. Revta bras. Zool. 16 (2): 483-487.

MASNER, L. 1993. Platygastroidea, p. 558-565. In: H. Goul.et \& J.T. Huber (Eds). Hymenoptera of the world: an identification guide to families. Ottawa, Agriculture Canada.

SChaufF, M.E.; J. LASAllL \& L.D. CoOTE. 1997. Eulophidae, p. 327-429. In: G. GibSon; J.T. Huber \& J.B. WOOL..FY (Eds). Annotated keys to the genera of Nearctic Chalcidoidea (Hymenoptera). Ottawa, NRC Research Press, 794p.

Silv^, J.G. DA \& G.V. SOMNER. 1984. A Vegetação de Restinga na Barra de Maricá, RJ, p. 217-224. In: L.D. DE LACERDA; R. CERQueira \& B. TURCQ (Eds). Restingas: Origem, Estrutura, Processos. Niterói, CEUFF, $475 p$. 